\title{
DAS SOBREASSEVERAÇÕES ÀS AFORIZAÇÕES: VEICULAÇÃO E INTERPRETAÇÃO DE FALAS NA MÍDIA ONLINE
}

(From surassertion to aphorization: circulation and interpratation of speeches in online media)

\author{
Raquel Tiemi Masuda Mareco ${ }^{1}$ \\ (Universidade Estadual de Maringá - UEM) \\ Andre William Alves de Assis ${ }^{2}$ \\ (Universidade Federal de Minas Gerais-UFMG)
}

\begin{abstract}
During a press conference after participating of V forum of BRICS, Dilma Rousseff briefly answered a question about inflation that spread quickly in the media, producing different meanings. Through this fact, we propose a discussion about the matter of discourse spread and its citation in online news. Regardful to surassertion and aphorisation processes, we observed that the operation Dilma's speech citation show discursive shunts which reveal the communication vehicle positioning, because they are altered and interpreted in different ways, without letting to be assign by the source-text enunciator.
\end{abstract}

Keywords: interpretation; aphorisation; surassertion; media.

RESUMO: Durante uma entrevista coletiva após sua participação no $V$ fórum dos BRICS, Dilma Rousseff respondeu brevemente a uma pergunta sobre inflação que circulou rapidamente na mídia produzindo diferentes sentidos. Diante desse fato, propomos uma discussão sobre a problemática da veiculação de falas e de suas retomadas em notícias online. Atentos aos processos de sobreasseveração e aforização, observamos que o funcionamento das retomadas dessas falas de Dilma revela manobras discursivas que evidenciam o posicionamento do veículo de comunicação, pois elas sofrem alterações e são interpretadas de maneiras diversas, sem deixar de serem atribuídas ao locutor do texto-fonte.

Palavras-chave: interpretação; aforização; sobreasseveração, mídia.

\section{Considerações iniciais}

Depois de participar do V Fórum dos BRICS (que reúne Brazil, Russia, India, China and South Africa, considerados países em desenvolvimento), realizado em Durban, na África, no dia 27 de março de 2013, a presidenta ${ }^{3}$ do Brasil, Dilma Rousseff, falou sobre a importância do evento em uma entrevista coletiva que durou, aproximadamente, 14 minutos.

\footnotetext{
${ }^{1}$ Doutoranda em Letras pela Universidade Estadual de Maringá (UEM). Mestre em Letras pela mesma instituição (UEM/CNPQ). Professora Assistente na Faculdade de Tecnologia do Estado de São Paulo (FATEC). Integra o Grupo de Estudos Políticos e Midiáticos (GEPOMI/UEM).

${ }^{2}$ Doutorando em Linguística pela Universidade Federal de Minas Gerais (UFMG/Capes). Mestre em Letras pela Universidade Estadual de Maringá (UEM). Integra o Núcleo de Análise do Discurso (NAD/FALE/UFMG), o Centro de Pesquisa Fórmulas e Estereótipos: Teoria e Análise (FEsTA/UNICAMP), e o Grupo de Estudos Políticos e Midiáticos (GEPOMI/UEM).

${ }^{3}$ Optamos pela utilização de presidenta em vez de presidente, acompanhando os usos nos sites oficiais do governo. Segundo o site do Planalto (2011), "a norma culta da língua portuguesa acata as duas formas como corretas e aceitáveis. De acordo com o dicionário Houaiss, 'presidenta' é o feminino de presidente, embora seja menos usual".
} 
Ao final, um dos jornalistas a questionou sobre a inflação no Brasil. Mesmo marcando em seu discurso que não queria falar sobre esse assunto naquele momento, Dilma respondeu e sua fala foi veiculada por diferentes mídias. Rapidamente, sua resposta repercutiu de forma negativa no mercado financeiro, que interpretou a fala como contrária às medidas de combate à inflação.

Pela polêmica instaurada, a assessoria de imprensa do Palácio do Planalto emitiu, no mesmo dia da fala de Dilma, uma convocação extraordinária aos jornalistas, a fim de que a presidenta falasse, especificamente, sobre a inflação. Nessa coletiva, Dilma falou com propósito de 'esclarecer' o significado de sua fala no BRICS e afirmou ter havido manipulação de sua fala por parte da imprensa. Essa segunda coletiva resultou a imediata retirada das notícias acusadas de serem manipuladas ${ }^{4}$ pelos veículos online. A partir de então, todos os veículos de comunicação passaram a veicular os mesmos enunciados com maior cautela.

Diante desse tipo de polêmica, recorrente na relação entre mídia e política, e de nosso interesse pelo estudo de enunciados políticos destacados na/pela mídia, propomos desenvolver aqui uma discussão sobre a problemática da veiculação de falas políticas e de suas interpretações por veículos midiáticos. Para essa discussão, embasamo-nos em estudos de Dominique Maingueneau (2008; 2010; 2011; 2014) sobre os enunciados destacados e destacáveis, em especial os conceitos de sobreasseveração e aforização propostos pelo autor.

Metodologicamente, iniciamos nosso estudo com a coleta do vídeo e da transcrição da entrevista em tela na íntegra, ambos disponibilizados no site da presidência da república (2013a; 2013b). Em seguida, observamos as ocorrências na mídia. Selecionamos, na internet, notícias online que retomavam a fala de Dilma na entrevista no BRICS, para que fosse possível confrontar os enunciados retomados pelas notícias com a fala da presidenta na entrevista. Partindo desse arquivo, discutimos a teoria dos enunciados destacados e destacáveis, e demonstramos como esses processos produzem sentidos no corpus proposto. Nossa hipótese é a de que as sobreasseverações, retomadas pelas mídias, são modificadas em graus diversos ao serem inseridas como aforizações, o que produz uma tensão entre a fala política (sobreasseveração) e o texto citado pela mídia online (aforização). Nesse sentido, o fio condutor dessa pesquisa consiste em responder quais são as manobras realizadas pela

\footnotetext{
${ }^{4}$ É interessante observar que a possibilidade de editar uma notícia já publicada, ou de retirá-la de circulação, é uma particularidade dos jornais e portais online (não nos interessa fazer aqui uma distinção entre eles). No caso de jornais impressos, essas manobras são impossíveis, restando apenas a possibilidade de uma retratação ou de uma errata na edição do dia seguinte. 
mídia online na reprodução dessas falas, observando seu funcionamento na relação interdiscursiva que as sobreasseverações e as aforizações estabelecem entre si.

Ressaltamos que este trabalho não propõe uma análise exaustiva, mas uma reflexão em torno de uma teoria, utilizando como exemplo um corpus que representa um cenário específico da política atual brasileira. Ele corresponde a uma parte de um trabalho maior desenvolvido por nós no âmbito do Grupo dos Estudos Políticos e Midiáticos - GEPOMI, na Universidade Estadual de Maringá (UEM), que congrega estudos em torno dos temas mídia, política e suas inter-relações na contemporaneidade.

\section{A destacabilidade}

A mídia, em geral, por meio de uma sofisticada maquinaria discursiva, coloca em circulação enunciados oriundos de fontes diversas. Esses enunciados provêm, muitas vezes, de seleções, de escolhas, de recortes (de falas, de frases, de textos), vindos de enunciações específicas. A fala de Dilma Rousseff (no que chamaremos de texto-fonte) é um exemplo de funcionamento dessa maquinaria, heterogênea em suas práticas e em sua constituição. Ao serem transportados para notícias online, esses recortes "produzem uma realidade criada por/para uma necessidade/intencionalidade enunciativa, que extrapola o momento temporal onde se encontra enraizado à enunciação" (ASSIS; MARECO, 2012: p. 3).

O processo que compreende a saída de um texto de uma enunciação à outra, Maingueneau (2010) denomina destextualização. As escolhas em torno de qual enunciado irá ou não circular estão relacionadas a fatores que vão desde características formais (rima, metáforas, posição no texto, etc.) até a própria gênese do discurso que impõe restrições a respeito do conteúdo selecionado, a depender do posicionamento discursivo da maquinaria midiática. Essas escolhas produzem sentidos diversos e a responsabilidade daquilo que coloca em circulação. Para Assis e Benites (2014, p: 89, inserção nossa),

[...] é dela [a maquinaria midiática] a palavra final sobre a seleção, a organização, o tom e a disposição espacial das informações a serem levadas a público, segundo critérios por ela decididos. Isso não significa que seu discurso seja homogêneo ou uniforme, pois [...] envolve setores e profissionais diversos e essa homogeneidade é, na verdade, uma ilusão.

Prática recorrente dessa maquinaria, o gênero notícia online nos parece ser um bom candidato para observar esse processo que compreende um mesmo enunciado (o recorte) 
perpassando enunciações distintas (o texto-fonte e a notícia online). As notícias online são compreendidas neste trabalho como um dos produtos da maquinaria midiático-discursiva, e sua prática discursiva não foge à tradição do jornalismo impresso, uma vez que compreende a seleção, tratamento e circulação de textos (ou falas) em forma de "notícia".

Quando um portal de notícias, como o G1, coloca em circulação o enunciado da figura 1, o leitor não dispõe, imediatamente, de ferramentas que permitam um resgate do texto original, destacado em forma de título da notícia online. Não há, portanto, o confronto entre o destaque e o que de fato fora pronunciado pelo ator político. Vejamos o exemplo:

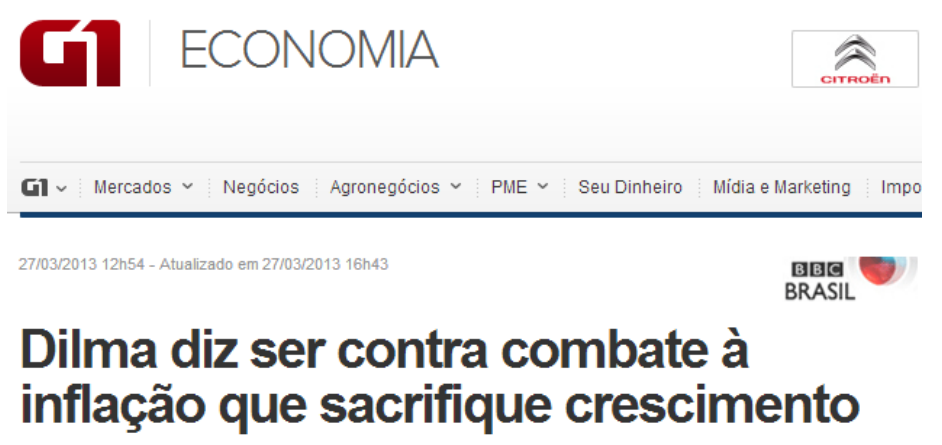

Figura 1: Enunciado destacado no portal G1.

A notícia que compõe a Figura 1 foi publicada na internet, ambiente que permite a inserção de links que direcionam o leitor a vídeos, imagens, sons, etc. São recursos possíveis dentro de uma plataforma que dá suporte à página da internet onde se veicula a notícia online. Esses recursos permitem, em certa medida, confrontar o relato da notícia com a fala gravada (em áudio ou vídeo) de Dilma. Entretanto, esse confronto não é recorrente na publicação de notícias como a da Figura 1. Um dos motivos dessa ausência está relacionado à credibilidade do veículo que afasta, ilusoriamente, a possibilidade de a fala relatada por eles ter sido outra.

Existem outros fatores que corroboram para o aumento dessa credibilidade, como o uso do discurso direto em "Dilma diz" (que pode ser intercalado com o indireto no corpo da notícia), das aspas, dos travessões, etc. Esses recursos são importantes na construção do corpo da notícia, embora não sejam nosso objeto de análise nesta discussão. Nosso objetivo principal consiste em observar o funcionamento de enunciados destacados, frutos de uma sobreasseverações (o texto-fonte, especificamente a fala da presidenta), posto em circulação sob forma de uma aforização destacada de um texto (citações em notícias online). 


\section{Sobreasseveração e aforização}

Uma temática muito presente nos trabalhos de Maingueneau diz respeito à destacabilidade enunciativa. De acordo com o autor, o destaque de alguns enunciados só é possível porque, dentro de uma lógica do texto, sobressaem-se algumas características formais: "são curtas, bem estruturadas, de modo a impressionar, a serem facilmente memorizáveis, e reutilizáveis" (MAINGUENEAU, 2008: 77). O autor se refere a um conjunto de características que classificam um enunciado como destacável ou passível de ser destacado. Esse conceito mais amplo da destacabilidade é de suma importância para que possamos compreender a Figura a seguir:

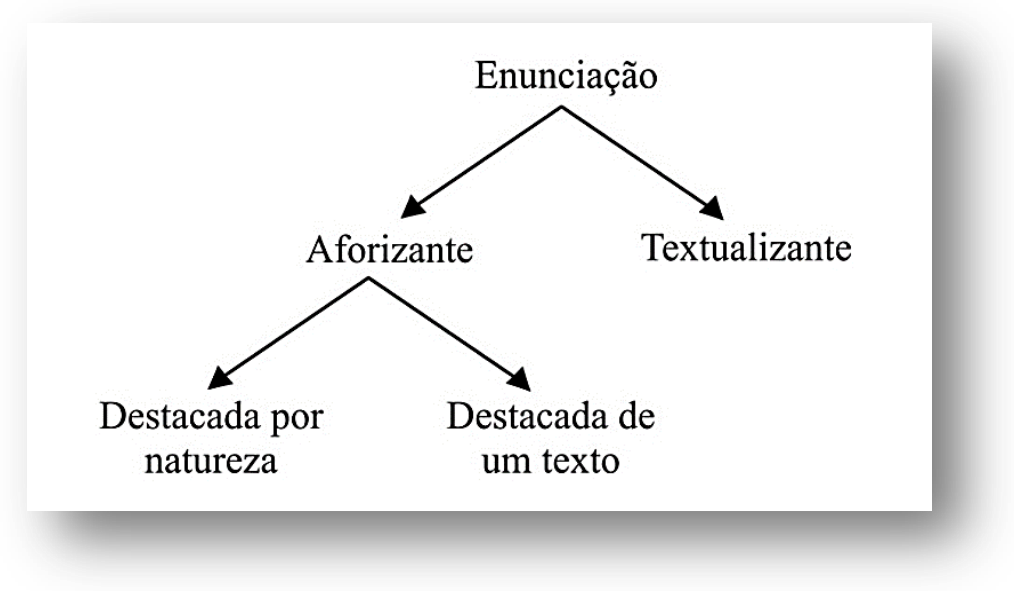

Figura 2: Enunciações Aforizante e Textualizante

Fonte: Maingueneau (2010)

A Figura 2 nos permite observar dois diferentes planos enunciativos: um textualizante e outro aforizante. Contudo, a aparente oposição entre os planos não os inscrevem em dimensões opostas. Na verdade, ambos estão inscritos no horizonte de um gênero discursivo, uma vez que todo enunciado se materializa em um gênero, mas as aforizações não estão presas aos gêneros. Elas precisam de um para existir, mas estão sempre em conflito com o plano textual que a acolhe, apontando para fora do texto. Essa leitura da Figura 2 nos permite observar que os enunciados destacados perpassam (por) ou emanam (de) um processo de textualização que compreende a produção de um quadro genérico.

Os enunciados destacados compõem esse quadro (enunciação textualizante), fazendo parte da lógica do texto, ou o perpassam (enunciação aforizante), sem fazer parte dessa lógica, 
mesmo que sejam inseridos em um texto. Nossa compreensão pode ser exemplificada na adaptação da figura abaixo:

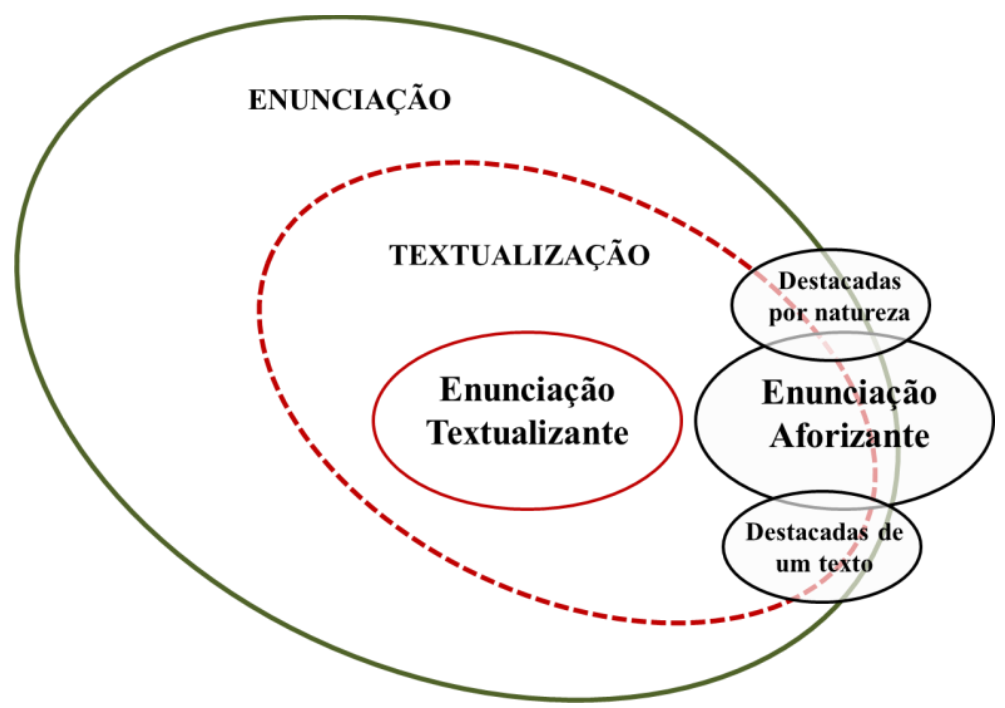

Figura 3: Representação do funcionamento das enunciações Aforizante e Textualizante.

Fonte: Adaptado de Maingueneau (2010).

Conforme demonstramos na Figura 3, o processo de textualização é necessário para a materialização de toda e qualquer enunciação, sua fonte discursiva. As enunciações aforizante e textualizante compõem seu próprio quadro genérico em que se manifestam. No entanto, as ocorrências das enunciações aforizante e textualizante são distintas porque existem a partir de duas lógicas também distintas: a lógica do texto e a lógica da citação. Na lógica do texto, os enunciados compreendem o plano textual do quadro genérico, não há fugas aparentes e os enunciados pretendem ser originais, inéditos. Os enunciados nessa lógica do tex to podem possuir características destacáveis; "esta destacabilidade, que abre a possibilidade de uma destextualização, de uma saída do texto, entra em tensão com a dinâmica da textualização e vai na direção oposta a integrar os constituintes em uma unidade orgânica (MAINGUENEAU, 2014: 15, grifos do autor)".

$\mathrm{Na}$ enunciação textualizante, seguindo o raciocínio de Maingueneau (2014), os enunciados se constituem como parte integrante dessa ordem do texto. Nesse sentido, as sobreasseverações, inscritas nesse regime textualizante, compõem o fundo textual que define e restringe as posições de produção e de recepção da cena genérica. As sobreasseverações são, portanto, enunciados que condensam uma tomada de posição de seu locutor dentro do texto e que possuem certa saliência, com a pretensão de fugir ao texto. Há na sobreasseveração "um 
tipo de amplificação de certas sequências do texto" (MAINGUENEAU, 2008: 89), o que caracteriza a marcação de um enunciado destacável pelo próprio autor do texto, marcado pelo posicionamento de uma fonte transcendente que se sobrepõe ao Eu.

Já na lógica que compreende o regime aforizante, a ordem discursiva não se prende à textualidade, "não há posições correlativas, mas uma instância que fala a uma espécie de 'auditório universal'” (MAINGUENEAU, 2010: 13). Com a pretensão de "escapar ao fluxo de comunicação, ser pura fala" (MAINGUENEAU, 2010: 13), a aforização não compreende o quadro delineado pelo gênero, ao contrário, foge a ele ao pretender ser livre, impondo uma repetição constitutiva na/pela memória discursiva que perpassa quadros genéricos em diferentes enunciações. Para Maingueneau (2010: 14), "a enunciação aforizante implica a utopia de uma fala viva sempre disponível, que atualiza o 'memorável': enunciando e mostrando que enuncia, ela se dá como parte de uma repetição constitutiva”.

Nesse regime aforizante, conforme figuras 2 e 4, estão dois tipos de enunciados destacados que se manifestam pela lógica da citação: a) os destacados por natureza, as máximas, os slogans, os provérbios, os ditos populares, etc.; b) os destacados de um texto, que remetem a um texto-fonte de onde são destacados enunciados que agrupam características destacáveis, sobreasseveradas ou não pelos enunciadores. São esses enunciados que possuem uma ligação com um texto-fonte, recuperável, que nos interessa nesse trabalho. Eles compreendem

[...] trechos curtos que funcionam de maneira autônoma, veiculando posicionamentos de grupos sociais específicos. Geralmente, são falas de pessoas com certo prestígio na sociedade, que circulam em diversos contextos ou enunciados conhecidos por pequenos grupos e que acabam sendo massificados (MARECO, PASSETI, 2014: 4).

Como é possível observar, "o enunciado destacável [a sobreasseveração] implica certa instância de enunciação e que o enunciado destacado [aforização] implica outra [...]" (MAINGUENEAU, 2008: 89, inserção nossa). Quando um portal de notícias online, como o exemplo da figura 1, retira de um plano textual um excerto para colocá-lo em circulação, ele o faz por suas características destacáveis, seja pela antecipação do destacamento seja pelo caráter polêmico, considerando um sistema de restrições semânticas que define o que pode ou não circular no interior de um posicionamento.

A mudança de um regime enunciativo para outro altera o contexto e a ordem do discurso. Essa descontextualização exige do leitor uma interpretação, que opacifica o seu sentido. Por isso, parece-nos importante estabelecer em um movimento teórico-analítico as 
diferenças entre esses dois principais processos: sobreasseveração e aforização. Vejamos como eles ocorrem no excerto a seguir:

\section{Excerto 1}

Eu, geralmente, nas questões específicas sobre inflação eu deixo para ser falada pelo ministro da Fazenda, mas eu vou te adiantar algumas questões. Eu não concordo com políticas de combate à inflação que olhem a questão da redução do crescimento econômico, até porque nós temos uma contraprova dada pela realidade. Nós tivemos um baixo crescimento no ano passado e houve um aumento da inflação porque teve um choque de oferta devido à crise. Um dos fatores era externo. Não tem nada que nós possamos fazer internamente, a não ser expandir a nossa produção, para conter o aumento dos preços das commodities derivado da quebra de safra nos Estados Unidos. Então, eu acho... São as mesmas vozes, talvez, não tem porque, não é... Você não escutou isso vindo do governo, nós não achamos que há essa relação, esse problema inflacionário que o Brasil teve, esse aumento um pouquinho... pleno emprego você vai resolver não é reduzindo o crescimento, vai resolver o pleno emprego... porque o Brasil também tem as suas dificuldades, nós temos uma demanda grande por emprego mais especializado, de maior qualidade, $\mathrm{e}$ temos uma sobra de emprego não especializado (BRASIL, 2013a, grifo nosso).

Ao ser questionada sobre a inflação no Brasil (excerto 1), Dilma hesita em sua fala, mas responde. Essa hesitação chama a atenção para a fala da presidenta, que produz uma sobreasseveração (trecho negritado por nós). Segundo Maingueneau (2011: 15), "a sobreasseveração não é uma citação, mas uma modulação da enunciação que formata um fragmento de texto como destacável, como candidato a uma 'destextualização'. É uma operação de realçamento do fragmento em relação ao contexto". O realce pode se realizar com a ajuda de marcadores diversos, como, por exemplo, uma generalização, frases de impacto, posição de destaque em uma unidade textual, repetições, uso de construções simétricas, metáforas ou paradoxos, utilização de conectores de reformulação (ou seja; em suma, etc.), entre outros (MAINGUENEAU, 2011).

Ao dizer "vou te adiantar algumas questões", Dilma dá destaque, realça sua fala, produzindo uma sobreasseveração que instiga a curiosidade sobre a informação que será por ela pronunciada. "Enunciado generalizante, propõe uma norma em tom solene. É o tipo de enunciado que se imagina que poderia facilmente ser citado" (MAINGUENEAU, 2014: 15). Esse realce produz ainda um sentido de novidade em primeira mão. Vejamos, como exemplo, outro trecho da resposta de Dilma em que também ocorre a sobreasseveração. 


\section{Excerto 2}

Então, eu acredito o seguinte: esse receituário que quer matar o doente em vez de curar a doença, ele é complicado, você entende? Eu vou acabar com o crescimento do país. Isso daí está datado, isso eu acho que é uma política superada. Agora, isso não significa que o governo não está atento e, não só atento, acompanha diuturnamente essa questão da inflação. Nós não achamos que a inflação está fora de controle, pelo contrário, achamos que ela está controlada e o que há são alterações e flutuações conjunturais. Mas nós estaremos sempre atentos.

Agora, por favor, por favor, vamos falar aqui... [interrompendo jornalista e pedindo para que voltasse a falar sobre o fórum dos BRICS] (BRASIL, 2013a, grifo nosso).

O trecho que destacamos em negrito volta a atenção para o enunciado que se segue "Eu vou acabar com o crescimento do país". O trecho negritado sugere que o que será dito é algo importante. Ao configurar sua enunciação dessa forma, Dilma torna parte de seu enunciado destacável em oposição ao restante do trecho. Normalmente, são as afirmações mais polêmicas, que marcam uma tomada de posição forte, polêmica, que serão destacadas. Ressaltamos que, na sobreasseveração, estamos falando do processo de tornar destacável um trecho no texto-fonte. Quando os enunciados, destacáveis ou não, ainda estão na lógica do texto, mas são marcadas por um Eu, que se revela em um posicionamento polêmico, forte, como quem antecipa seu destacamento na intenção de passar a circular em outros lugares enunciativos, em gêneros diversos, marcados por uma retomada. Quando isso acontece, ou seja, quando esse enunciado é efetivamente selecionado para compor outros gêneros (uma notícia, uma legenda de canal de TV, a capa de uma revista), nesse caso estamos falando de outro processo enunciativo: a aforização.

Mesmo que os trechos sobreasseverados e aforizados sejam semelhantes ou idênticos (em relação ao texto-fonte e sua retomada), não podemos dizer que são os mesmos enunciados, pois a enunciação é outra. Isso quer dizer que, ao circularem em outros lugares enunciativos, outros gêneros, um mesmo enunciado pode produzir diferentes sentidos. Vejamos um exemplo de como o trecho do excerto 2, sobreasseverado por Dilma, foi aforizado pelo jornal Gazeta do Povo (GP). 


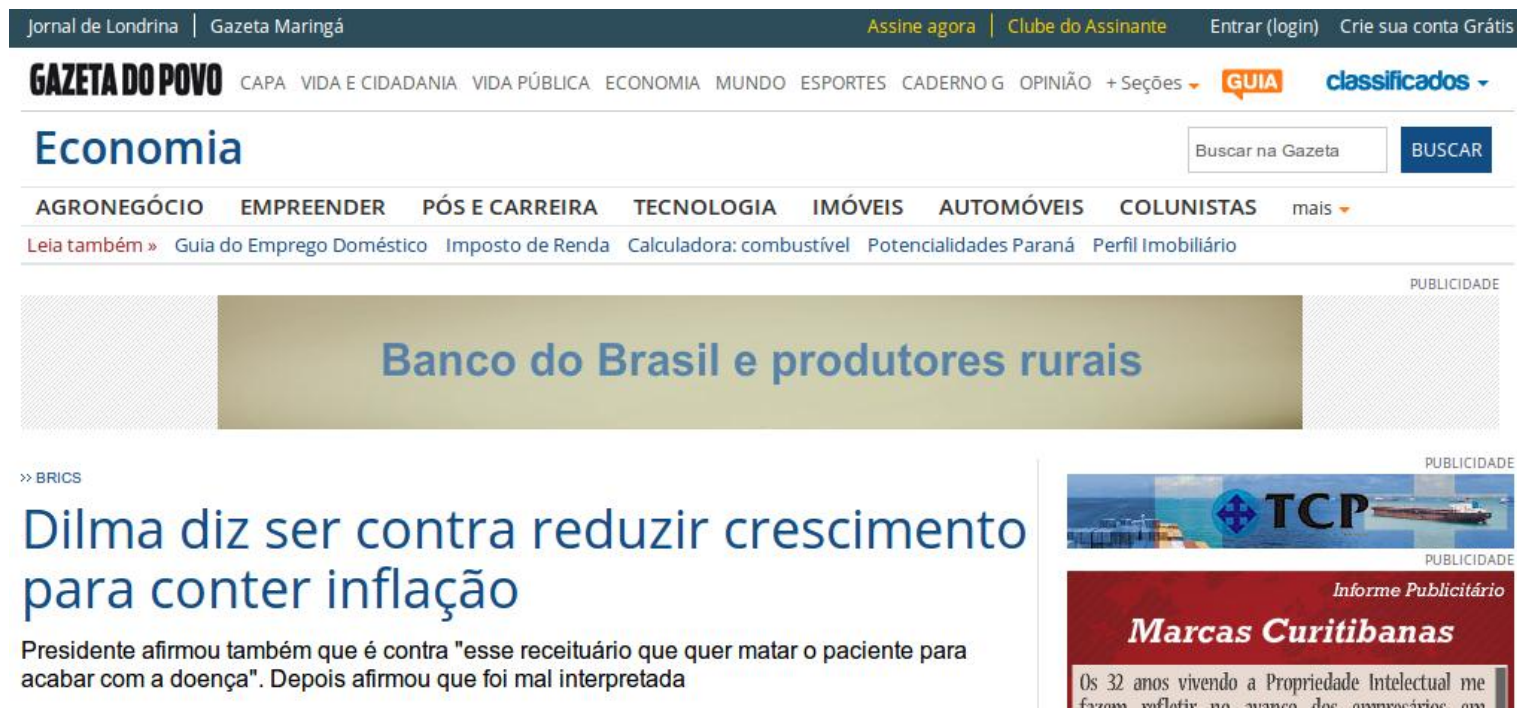

Figura 4. Enunciados destacados na Gazeta do Povo.

Como podemos observar na Figura 4, o enunciado destacado abaixo do título, "esse receituário que quer matar o pacienta para acabar com a doença” retoma, quase que exatamente, parte do excerto 2. Contudo, ao apresentar apenas esse recorte, acompanhado do título "Dilma diz ser contra reduzir crescimento para conter inflação" e do comentário "Depois afirmou que foi mal interpretada", o jornal online atribui ao trecho aforizado sentidos bem diferentes dos produzidos pela sobreasseveração do texto-fonte. O título limita os sentidos da metáfora utilizada por Dilma "esse receituário que quer matar o paciente [reduzir crescimento] para acabar com a doença [inflação]", ao silenciar algumas partes (que marcamos entre colchetes). O jornal atribui, portanto, outro sentido ao trecho destacado, não sendo possível o resgate dos referentes que consta na fala de Dilma. Mesmo assim, a GP o insere entre aspas na notícia. O uso das aspas afasta, nesse contexto, ilusoriamente, a possibilidade de o enunciado não ter sido exatamente o publicizado pela notícia online, pois produz um sentido de legitimidade, visto que mantém a responsabilidade do dizer na sobreasseveradora, Dilma Rousseff.

Por vezes, essas alterações de sentidos podem se processar por manobras que, ao aforizar um enunciado, alteram ainda mais o texto-fonte. Retomemos parte do excerto 1 referente ao título desta notícia: "Eu não concordo com políticas de combate à inflação que olhem a questão da redução do crescimento econômico". Podemos observar que o jornal online, altera a ordem da sobreasseveração de Dilma. Como vimos no excerto 1, Dilma disse ser contra reduzir crescimento para conter inflação. Na Figura 4, Gazeta do Povo inverte o par da restritiva: inflação - crescimento. Essa alteração se dá por uma manobra de topicalização, 
de pôr em evidência um elemento no texto, que é deslocado para a posição inicial (GONÇALVES, 1998). Trazida para o início da frase "crescimento" é topicalizado, dando maior destaque ao termo que, na fala de Dilma, poderia confundir o leitor ao figurar em posição final.

Ser "contra reduzir crescimento para conter inflação", traz o foco da discussão para o "crescimento" do país, que pode ser compreendido como algo positivo: se o país cresce, as empresas crescem e as pessoas crescem. Vejamos mais um exemplo, para que possamos prosseguir com nossas discussões:

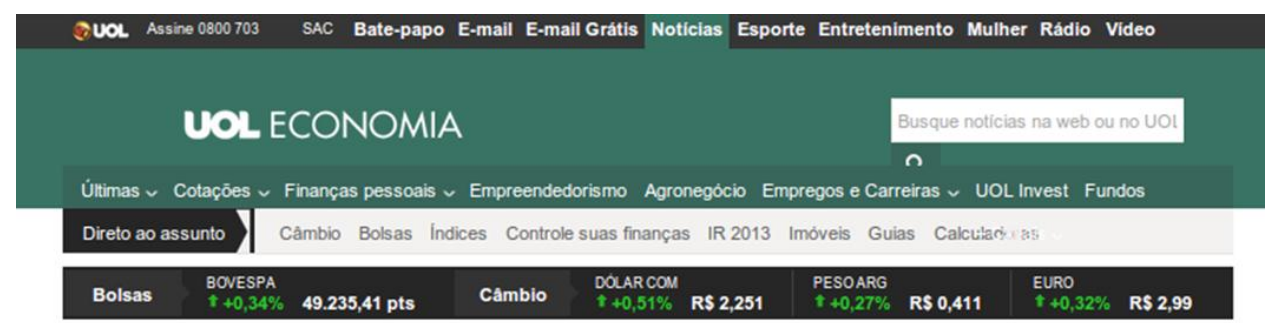

\section{Dilma diz ser contra combate à inflação que sacrifique crescimento}

Figura 5: Enunciados destacados na Gazeta do Povo.

A importância da ordem dos termos pode ser melhor compreendida se considerarmos os exemplos da Gazeta do Povo (GP), na figura 4, e o exemplo do UOL, na figura 5. A escolha pela topicalização de "crescimento" na GP marca uma tomada de posição do jornal, muda o sentido da frase e gera efeitos positivos à fala de Dilma Rousseff, afastando uma polêmica negativa da afirmação (re)criada pelo jornal. Esse é um exemplo de aforização atribuída a Dilma Rousseff que não fora sobreasseverada por ela. A maquinaria midiática (co)constrói esse processo por meio de uma interpretação da fala (ASSIS, 2013).

Já no título do UOL, que obedece à ordem das orações do texto-fonte, podemos observar que os efeitos produzidos são mais negativos, marcam uma polêmica negativa em torno da afirmação. No título da Gazeta do Povo, Dilma é contra "reduzir crescimento", enquanto no do UOL ela é contra "combate à inflação". O imaginário histórico-social do brasileiro reflete uma imagem bastante negativa em torno do termo "inflação", por isso a opção pela transferência para o final da frase altera os sentidos da fala de Dilma em GP, sendo mais favorável a ela, enquanto no UOL a manutenção da ordem parece ser mais desfavorável à Dilma. 
Maingueneau (2008: 86) afirma que “a autonomização da sobreasseveração em relação ao texto de origem vai ainda mais longe quando existe uma transformação do enunciado, ou de um ou outro de seus parâmetros enunciativos, quando ele passa ao paratexto". Esses processos vêm sendo discutidos, descritos e classificados em pesquisas atuais de autores como Assis e Mareco (2012) Assis (2013), Mareco (2013), Assis e Benites (2014), Mareco e Passetti (2014). De forma geral, eles demonstram que as aforizações veiculadas pela mídia são, na maioria dos casos, interpretações de falas que sofrem, de forma mais ou menos intensa, alterações. Dessa forma, o resgate de um trecho sobreasseverado ou não traz consigo mais elementos linguísticos e discursivos do que apenas adaptações entre as modalidades da língua nas falas de atores políticos.

Como vimos no início deste trabalho, durante a entrevista coletiva, após a reunião dos países BRICS, um repórter perguntou à Dilma sobre a inflação no Brasil. A presidenta hesitou, mas acabou por responder brevemente à pergunta. De toda a fala de Dilma durante a coletiva, cerca de 14 minutos, o que circulou imediatamente foi a afirmação polêmica de que ela seria contra às medidas de controle da inflação. Por mais que os atores políticos saibam que suas falas serão sempre objeto de retomada pela mídia, algumas delas podem coloca-los em polêmicas criadas pela mídia e não por suas falas. "Por mais que políticos queiram, muitas 'pequenas frases' que a mídia faz circular são fragmentos de textos que seu autor teria preferido que ficassem na sombra", assevera Maingueneau (2014: 17).

Frente à polêmica instaurada, Dilma convocou outra coletiva e se posicionou em relação à circulação de sua fala ao escrever no Blog do Planalto (2013): "Foi uma manipulação inadmissível de minha fala. O combate à inflação é um valor em si mesmo e permanente do meu governo". Esse enunciado, que marca uma tomada de posição, produzindo uma sobreasseveração, passou a circular, imediatamente à postagem no blog, em lugares enunciativos diversos, produzindo efeitos também diversos. Vejamos um exemplo: 


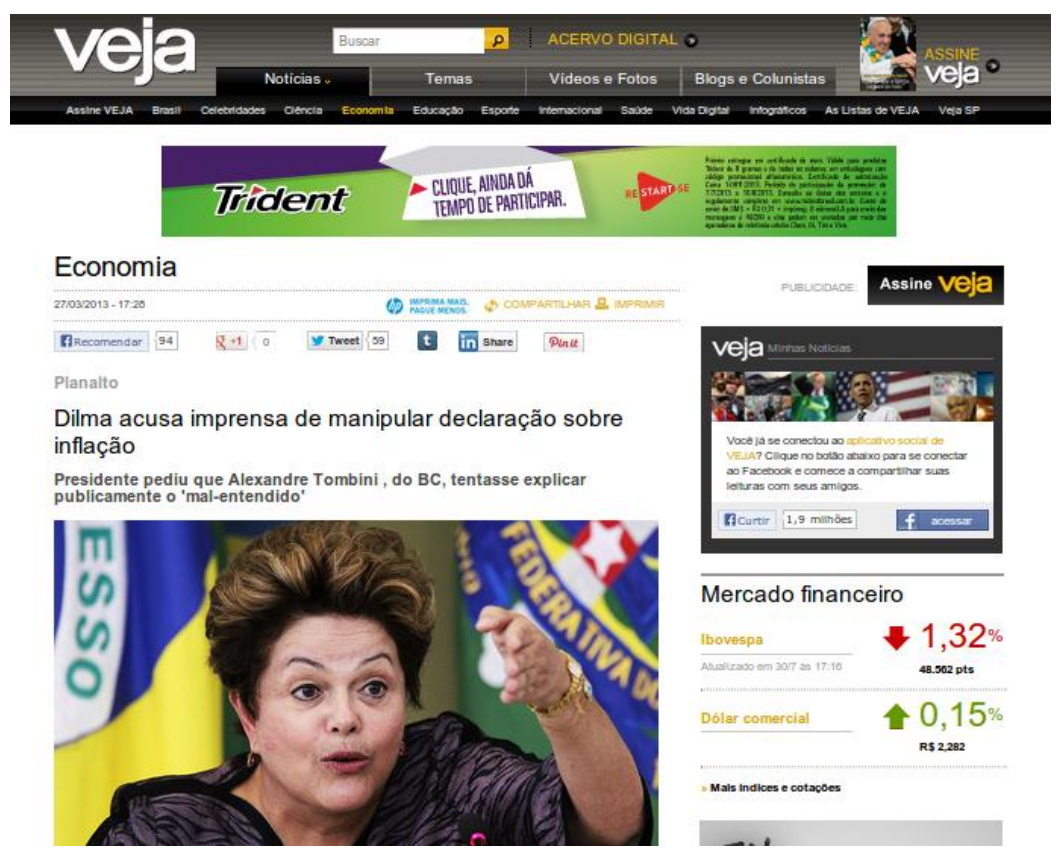

Figura 6: Enunciados destacados na Veja.

Ao citar a fala de Dilma, Veja Online veiculou esse título (Figura 6) que classifica a fala da presidenta como "acusação". O portal de notícias apresenta o que seria uma extração de um excerto de fala em forma de aforização: "Dilma acusa imprensa de manipular declaração sobre inflação". O tom de "defesa" na afirmação de Dilma, contextualizado em resposta às críticas em torno da manipulação de sua fala, é transformado em um tom de acusação por Veja. A acusação é confirmada pela foto de Dilma, que contribui para a (re)afirmação dos sentidos produzidos por esse veículo. Aparentemente, ela está nervosa: seu rosto fechado, ombros altos, braço e mão rígidos, como quem aponta para alguém e acusa. Para Maingueneau (2010: 15), "partindo do postulado de que a aforização resulta de uma operação de destacamento que é pertinente, o leitor deve construir interpretações que permitam justificar esta pertinência.". Nesse sentido, a foto de Dilma contribui para a veiculação de uma interpretação da fala de Dilma, em torno de um tom de acusação, que é a interpretação do jornal.

Embora não seja nosso interesse nos aprofundar em uma análise da imagem, somos levados a considerar que o uso da foto na notícia (figura 6) teria uma dupla função: a) identificar Dilma Rousseff e atribuir a ela a responsabilidade da fala, o que reforça a aforização. De acordo com Maingueneau (2010: 16) "a foto autentica a aforização do locutor como sendo sua fala, aquela que faz dele um Sujeito plenamente responsável”; b) instaurar e validar uma cenografia que comprove e sustente o tom de acusação interpretado e veiculado pela revista. Dessa forma, a imagem em destaque na notícia e o recorte de fala (co)constroem 
a aforização: o tom da fala é interpretado e veiculado por Veja como acusação, a imagem (atemporal, pois não sabemos quando foi tirada) é utilizada para validar o tom de acusação instaurado por essa interpretação, validando o discurso da revista.

\section{Considerações finais}

Considerando a problemática da circulação de enunciados, selecionamos como objeto de análise os processos de sobreasseveração e aforização. Apresentamos dois trechos que representam a fala de Dilma Rousseff, presidenta do Brasil, que compõem nosso corpus. $\mathrm{Na}$ sequência, apresentamos enunciados que retomam essas falas em jornais e revistas online, por meio de recortes.

Embora a teoria vigente seja pouco difundida, acreditamos ter sido possível, em um movimento teórico-analítico, observar o funcionamento dos regimes enunciativos aforizante e textualizante, que contemplam os processos de aforização e sobreasseveração. Esse percurso nos permitiu elaborar um esquema (figura 3) que representa o funcionamento dos enunciados destacados: o processo de retomada de enunciados que se inicia na sobreasseveração (num dado texto-fonte) e (per)passa a aforização (circulando em diferentes lugares enunciativos, diferentes gêneros). Em nosso corpus, as aforizações foram oriundas de sobreasseverações de falas, ou seja, enunciados destacados de um texto-fonte falado.

Há, nesse material, uma relação interdiscursiva que gera tensão entre o texto de saída (sobreasseveração) e o texto de chegada (aforização) que compõe as notícias. Os exemplos de notícias online nos permitiram observar que, no processo de destextualização, operam-se manobras que resultam em alteração de sentido das falas, sobreasseveradas no texto-fonte e aforizadas nas notícias, manobras que geram o conflito. Com base no corpus analisado neste trabalho, demonstramos o funcionamento de duas principais manobras: a) alteração da ordem das orações, que entre aspas afastam a possibilidade de a fala não ser realmente aquela, ao mesmo tempo em que evidenciam o posicionamento do veículo por meio da manobra discursiva de pôr em destaque o que marca uma posição e pode gerar (mais ou menos) polêmica e b) mudança de tom, que transforma uma fala de defesa, em um contexto, em uma fala de acusação na notícia.

Dessa forma, podemos concluir que a mídia, tanto se apropria de sobreasseverações para colocar em circulação falas de atores políticos, quanto produz sobreasseverações, que podem ser atribuídas a um sobreasseverador empírico, mesmo que a fala não esteja de acordo com o que fora pronunciado. Por fim, essas manobras apagam ilusoriamente a possibilidade 154 
de o texto ser outro, seja pela credibilidade do jornal, seja por essas manobras linguísticas utilizadas por essa sofisticada maquinaria que produz notícias online.

Recebido em: dezembro de 2014 Aprovado em: maio de 2015 rachel.mareco@gmail.com assis.awa@gmail.com

\section{Referências bibliográficas}

ASSIS, A. W. A.; MARECO, R. T. M. Enunciados em destaque: caminhos para uma abordagem em análise do discurso. Linguasagem, São Paulo, v. 19, n. 2, p. 1-8, 2012.

ASSIS, A. W. A. Citações e sobreasseverações: o funcionamento da retomada de falas em notícias online. 2013. 99 f. Dissertação (Mestrado em Letras). Universidade Estadual de Maringá, Maringá, 2013.

ASSIS, A. W. A.; BENITES, S. A. L. Uma maquinaria discursiva de recenografar falas. Linguagem em (Dis)curso, Tubarão, v. 14, n. 1, p. 85-104, jan./abr., 2014.

BLOG DO PLANALTO. Dilma acusa imprensa de manipular declaração sobre inflação. $2013 . \quad$ Disponível em: $<$ http://blog.planalto.gov.br/index.php?s=manipula\%C3\%A7\%C3\%A3o+de+fala\&btn_sub=B uscar>. Acesso em: 4 abr. 2013.

BRASIL. Uso da palavra "Presidenta". 2011. Disponível em: <http://www2.planalto.gov.br/presidenta/uso-da-palavra-presidenta>. Acesso em: 28 mar. 2013.

BRASIL. Entrevista coletiva concedida pela Presidenta da República, Dilma Rousseff, após declaração à imprensa - Durban/África do Sul. 2013a. Disponível em: $<$ http://www2.planalto.gov.br/multimidia/galeria-de-videos/video-da-entrevista-coletivaconcedida-pela-presidenta-da-republica-dilma-rousseff-apos-declaracao-a-imprensa-durbanafrica-do-sul/view>. Acesso em: 28 mar. 2013.

BRASIL. Vídeo da entrevista coletiva concedida pela Presidenta da República, Dilma Rousseff, após declaração à imprensa - Durban/África do Sul. 2013b. Disponível em: < http://www2.planalto.gov.br/multimidia/galeria-de-videos/video-da-entrevista-coletivaconcedida-pela-presidenta-da-republica-dilma-rousseff-apos-declaracao-a-imprensa-durbanafrica-do-sul/view>. Acesso em: 28 mar. 2013. 
G1. Dilma diz ser contra combate à inflação que sacrifique crescimento. 2013. Disponível em: <http://g1.globo.com/economia/noticia/2013/03/dilma-diz-ser-contra-combate-a-inflacaoque-sacrifique-crescimento-1.html>. Acesso em: 4 abr. 2013.

GAZETA DO POVO. Dilma diz ser contra reduzir crescimento para conter inflação. 2013. Disponível em: http://www.gazetadopovo.com.br/economia/conteudo.phtml?id=1357567\&tit=Dilma-diz-sercontra-reduzir-crescimento-para-conter-inflacao>. Acesso em: 4 abr. 2013.

GONÇALVES, C. A. Foco e topicalização: delimitação e confronto de estruturas. Revista de Estudos da Linguagem, Belo Horizonte, v.7, n. 1, p. 31-50, jan./jun., 1998.

MAINGUENEAU, D. Citação e Destacabilidade. In: MAINGUENEAU, D. Cenas da enunciação. POSSENTI, S.; SOUZA E SILVA, M. C. P. (Orgs.). São Paulo: Parábola, 2008. pp. 75-92.

Aforização. In: MAINGUENEAU, D. Doze conceitos em análise do discurso. SOUZA E SILVA, M. C.; POSSENTI, S. (Orgs.). São Paulo: Parábola, 2010. pp. 9-24.

Aforização, enquadramento interpretativo e configuração humanista. Trad. de Adriane Ribeiro Andaló Tenuta, Jean Cristtus Portela e Matheus Nogueira Schwartzmann. Coleção Mestrado em Linguística, Franca, v. 6, p. 15-34, 2011.

Frases sem texto. Trad. de Sírio Possenti et alii. São Paulo: Parábola, 2014.

MARECO, R. T. M. Do debate televisivo ao jornal impresso: aforizações na mídia nacional. 2013. 123 f. Dissertação (Mestrado em Letras). Universidade Estadual de Maringá, Maringá, 2013.

MARECO, R. T. M.; PASSETTI, M. C. C. Destextualização: Processo de Construção de Aforizações. Glauks, Viçosa, v. 14, n. 1, p. 1-16, 2014.

UOL. Dilma diz ser contra combate à inflação que sacrifique crescimento. 2013. Disponível em: <http://economia.uol.com.br/noticias/bbc/2013/03/27/dilma-diz-ser-contra-combate-ainflacao-que-sacrifique-crescimento.htm>. Acesso em: 4 abr. 2013. 